\title{
Another Story with a Burning Barn in It
}

I was on the porch pinching back the lobelia like trimming a great blue head of hair.

We'd just planted the near field, the far one the day before. I'd never seen it so clear,

so gusty, so overcast, so clear, so calm.

They say pearls must be worn or they lose their luster,

and that morning I happened to remember, so I put them on for milking, finding some

sympathy, I guess, between the two.

Usually I don't sit down until much later in the day.

The lobelia was curling in the sun. One by one birds flew off, and that should have been a sign.

Trust is made and broken. I hardly sit down at all. It was the time of year for luna moths,

but we hadn't had any yet settling on the porch or hovering above the garden I'd let the wild rose take. 